\title{
Clinical and Molecular Features Associated with Cystic Visceral Lesions in Von Hippel-Lindau Disease
}

\author{
Simon R.J. Taylor ${ }^{*}, 1,2,3,4$, Jasmin Singh ${ }^{4}$, Mandeep S. Sagoo ${ }^{4,5,6}$ and Sue L. Lightman ${ }^{4,5}$ \\ ${ }^{I}$ Division of Immunology \& Inflammation, Faculty of Medicine, Imperial College London, London, UK \\ ${ }^{2}$ Imperial College Healthcare NHS Trust, Hammersmith Hospital, Du Cane Road, London, UK \\ ${ }^{3}$ Royal Surrey County Hospital NHS Trust, Guildford, UK \\ ${ }^{4}$ Moorfields Eye Hospital, London, UK \\ ${ }^{5} U C L$ Institute of Ophthalmology, London, UK \\ ${ }^{6}$ Barts and the London NHS Trust, St. Bartholomew's Hospital, West Smithfield, London, UK
}

\begin{abstract}
Background: Von Hippel-Lindau (VHL) is an uncommon oncogenic disorder which occurs as a result of genetic mutations on chromosome 3p. Retinal capillary haemangiomas and CNS haemangioblastomas have been wellcharacterised in genotypic-phenotypic analyses, but cystic visceral lesions are less common and have been less frequently studied. The aim of this study was to perform genotypic and phenotypic analysis of a cohort of VHL patients that developed cystic visceral lesions to determine whether their genotype differs from that seen in other manifestations of VHL and whether the ocular manifestations differ.

Methods: This study reports a prospective case series of twenty-one patients identified from the Hammersmith Hospital Genetics Service database as having VHL mutations. Patients underwent regular ocular and systemic screening as well as genotypic analysis. The main outcome measures were the development of VHL lesions, either ocular or systemic.

Results: Cystic visceral lesions were detected in six of the 21 patients from the clinic (29\%). These included renal cysts in four patients, pancreatic cysts in three patients, and an epididymal cystadenoma in one patient. Renal cysts were not associated with any specific genotype. Pancreatic cysts appeared to occur in association with VHL gene deletions and all developed CNS haemangioblastomas. Only one patient developed ocular manifestations, which occurred in this patient in the form of two retinal capillary haemangiomas.
\end{abstract}

Conclusions: VHL gene deletions appeared to be associated with pancreatic cysts and the development of CNS haemangioblastomas. Ocular manifestations are uncommon in this group of patients.

Keywords: von Hippel-Lindau, retinal capillary haemangioma, epididymal cyst, renal cyst, gene deletion.

\section{INTRODUCTION}

Von Hippel-Lindau disease (VHL) is a rare, multisystem, oncogenic disorder. Morphologically, it is characterised by multiple lesions of varying histological types [1-4], including benign cysts, benign vascular tumours and malignant tumours. There are six organ systems which are mainly affected, the CNS (Central Nervous System), retina, pancreas, kidney, adrenal gland and epididymis, and there are varying manifestations in each $[1,5]$. Variable intra- and inter-familial expressivity is typical of VHL disease [6], but correlations have been demonstrated between mutational genotype and phenotype. For instance, deletions are associated with a low risk of pheochromocytoma, in contrast to missense mutations [1, 7-9]; a higher frequency of renal involvement has also been reported in truncating mutations compared to missense mutations [10]. Similarly, the risk of

*Address correspondence to this author at the Imperial College London Faculty of Medicine, Room 5N8B, 5th Floor Commonwealth Building, Hammersmith Hospital, London W12 0NN, UK; Tel: +44 (0) 1483 464192; Fax: +44 (0) 1483 464189; E-mail: s.r.taylor@imperial.ac.uk retinal capillary haemangioma $(\mathrm{RCH})$ is also affected by the genotype, occurring in $38 \%$ of patients with missense mutations and $40 \%$ of those with truncating mutations, but only $14 \%$ of those with deletions [11]. It has also been reported that truncating mutations lead to an earlier age of onset of RCH compared to missense mutations and deletions [12].

However, the ocular manifestations of VHL which occur in patients with visceral cysts are much less well characterised and have not previously been reported. The aim of this study was to determine the ocular phenotype of patients identified as having visceral cysts and to assess any relationship with the underlying genotype.

\section{METHODS}

In this study, we report a prospective case series of proven VHL disease gene carriers under the care of the VHL clinic at the Hammersmith Hospital, London, UK. Patients were eligible for inclusion in this study if they were undergoing follow-up in the VHL clinic and had proven VHL mutations on genotyping. Eligible participants were 
invited for ophthalmic screening in addition to their routine systemic screening. At the initial clinic visit, a retrospective review of the case notes was undertaken. Data relating to ocular and systemic disease manifestations were then collected prospectively for two years. The type of VHL mutation was documented in each case, VHL mutations being categorised as missense mutations, truncating mutations, or deletions.

VHL disease features were noted and categorised into one of four groups: cystic visceral lesions, other visceral lesions, CNS manifestations and ocular features. All patients had a good fundal view and a complete ophthalmic examination was carried out at the first and all subsequent clinic visits, including indirect peripheral retinal examination. All fundal lesions were documented by colour fundus photography and fundus fluorescein angiography was performed when the diagnosis of a retinal capillary haemangioma was uncertain.

\section{RESULTS}

Twenty-one patients were identified from the VHL clinic as carrying VHL disease genes and were thus eligible for inclusion in the study. All twenty-one agreed to participate in the study and to attend for ophthalmological screening. Of the 21 patients, eleven $(52 \%)$ were male and ten $(48 \%)$ were female. Twelve patients (57\%) were Asian and nine (43\%) were Caucasian; there were no patients of African or AfroCaribbean descent. The mean age at the time of VHL diagnosis was 25 years (range, 6 to 59 years), but patients with RCH were diagnosed at a younger age (mean 17 years vs 29 years for patients without RCH).

Six of the twenty-one patients (29\%) either presented with visceral cysts or developed them during the follow-up period of two years. Disease manifestations and associated mutational genotypes are summarised in Table 1. One patient presented with an epididymal cystadenoma and one presented with a renal cyst. Three patients developed pancreatic cysts during follow-up and three patients developed renal cysts. All of these patients who developed pancreatic cysts had VHL gene deletions and all developed
CNS HGB at some stage. Only one of the six patients developed ocular manifestations of VHL, namely retinal capillary haemangiomas; none of the other patients developed any ocular manifestations.

\section{DISCUSSION}

We performed a study of patients with an atypical manifestation of VHL, namely visceral cysts, followed in a Genetics Clinic. Owing to their relatively benign nature, cystic visceral lesions have received comparatively less attention in relation to both their correlation with other phenotypic manifestations of VHL disease and genotypic associations. Cystic visceral lesions were detected in six of the 21 patients in the clinic (29\%). These included renal cysts in four patients, pancreatic cysts in three patients, and an epididymal cystadenoma in one patient.

There are two case reports in the literature of epididymal cysts forming the first clinical manifestation of VHL [13, 14], one of which occurred in association with early-onset renal cell carcinoma. Epididymal cystadenomas have no established genotypic association [15], and we had only one patient with this manifestation in our cohort. Renal cysts are usually asymptomatic and found on screening in approximately $15 \%$ of patients with VHL disease $[4,16]$. They are considered precursors to malignancy, but transformation appears uncommon [15]. In this study group, renal cysts were not associated with any specific genotype. Pancreatic cysts are also usually asymptomatic and detected on systemic screening; their reported prevalence varies from $15 \%$ to $74 \%$ of patients with VHL disease, with one recent systematic review finding an overall prevalence of $60 \%$ [17$20]$. In our study, 3 patients (14\%) had pancreatic cysts. All of these patients had VHL gene deletions and all developed CNS HGB at some stage. This association has been previously reported, but only one study contains genotypic data $[17,21]$.

The small numbers of patients included in our study and limited follow-up make it impossible to make any definitive conclusions about the genotypes and phenotypes of visceral

Table 1. Disease Manifestations at Presentation and During Follow-Up for Patients with Cystic Visceral Lesions

\begin{tabular}{|c|c|c|c|c|c|c|c|c|c|}
\hline 1 & MissenseExon 1 & $\begin{array}{c}\text { Epididymal } \\
\text { cystadenoma }\end{array}$ & & & & $\begin{array}{c}\text { Renal } \\
\text { cyst }\end{array}$ & & & $\begin{array}{c}2 \times \text { Right } \\
\text { peripheral RCH }\end{array}$ \\
\hline 2 & $\begin{array}{l}\text { Missense } \\
\text { (variant) }\end{array}$ & Renal cyst & & & & & $\begin{array}{l}\text { Bilateral } \\
\text { PCC }\end{array}$ & & \\
\hline 4 & Deletion Exon 3 & & & $\begin{array}{l}\text { Spinal cord } \\
\text { HGB }\end{array}$ & & $\begin{array}{l}\text { Renal } \\
\text { cyst }\end{array}$ & & $\begin{array}{c}\text { Cerebellar } \\
\text { HGB }\end{array}$ & \\
\hline 5 & Deletion Exons 1-3 & & & $\begin{array}{l}\text { Cerebellar } \\
\text { HGB }\end{array}$ & & $\begin{array}{c}\text { Pancreatic } \\
\text { cyst } \\
\text { Renal cyst }\end{array}$ & & & \\
\hline
\end{tabular}

HGB, haemangioblastoma; PCC, phaeochromocytoma; $\mathrm{RCH}$, retinal capillary haemangioma. 
cystic lesions. Nevertheless, our study does provide some supporting evidence for the previously observed phenotype comprising pancreatic cysts and CNS HGB linked to VHL deletions. In addition, one of our principal aims in performing this study was to see whether there was any association between visceral cystic lesions and ocular involvement. Although our small numbers again require us to be guarded in our conclusions, our failure to find any association suggests that further ocular study of a larger population of patients with visceral cystic lesions would be unlikely to prove rewarding.

In conclusion, we present the findings of clinical and molecular examination of a small group of patients with visceral cystic lesions in VHL disease. Pancreatic cysts appeared to be associated with VHL deletions, but ocular involvement was uncommon in this group of patients.

\section{SUMMARY}

This paper describes the phenotype of a cohort of patients with von Hippel-Lindau disease who developed visceral cystic lesions. Genotyping results suggested that VHL gene deletions may be associated with pancreatic cysts and the development of central nervous system haemangioblastomas. Ocular manifestations proved uncommon in this group of patients.

\section{ACKNOWLEDGEMENT}

Grants/Funding: The authors gratefully acknowledge the support of Prof Patrick Maxwell and Prof Huw Dorkins of the Hammersmith Hospital von Hippel-Lindau clinic. This study was approved by the Hammersmith Hospital and Queen Mary's Hospital Research Ethics Committee. S.R.J. Taylor was supported by the UK National Institute of Health Research, and this research was supported by the Imperial NIHR Comprehensive Biomedical Research Centre. The sponsor or funding organization had no role in the design or conduct of this research. The authors report no conflicts of interest.

\section{CONFLICT OF INTEREST}

The authors confirm that this article content has no conflicts of interest.

\section{REFERENCES}

[1] Neumann HP, Lips CJ, Hsia YE, Zbar B. Von Hippel-Lindau syndrome. Brain Pathol 1995; 5(2): 181-93.
[2] Maher ER, Yates JR, Harries R, et al. Clinical features and natural history of von Hippel-Lindau disease. Quart J Med 1990; 77(283): 1151-63.

[3] Choyke PL, Glenn GM, Walther MM, Patronas NJ, Linehan WM, Zbar B. von Hippel-Lindau disease: genetic, clinical, and imaging features. Radiology 1995; 194(3): 629-42.

[4] Lonser RR, Glenn GM, Walther M, et al. von Hippel-Lindau disease. Lancet 2003; 361(9374): 2059-67.

[5] Joshi L, Taylor SR, Lightman S. The eye and phacomatoses. Br J Hosp Med (Lond) 2011; 72(12): 677-81.

[6] Schimke RN, Collins DL, Stolle CA. Von Hippel-Lindau Syndrome. In: Pagon RA, Bird TD, Dolan CR, Stephens K, Eds. Seattle (WA): GeneReviews 1993.

[7] Neumann HP, Bender BU. Genotype-phenotype correlations in von Hippel-Lindau disease. J Int Med 1998; 243(6): 541-5.

[8] Zbar B, Kishida T, Chen F, et al. Germline mutations in the Von Hippel-Lindau disease (VHL) gene in families from North America, Europe, and Japan. Hum Mutat 1996; 8(4): 348-57.

[9] Chen F, Kishida T, Yao M, et al. Germline mutations in the von Hippel-Lindau disease tumor suppressor gene: correlations with phenotype. Hum Mutat 1995; 5(1): 66-75.

[10] Gallou C, Chauveau D, Richard S, et al. Genotype-phenotype correlation in von Hippel-Lindau families with renal lesions. Hum Mutat 2004; 24(3): 215-24.

[11] Wong WT, Agron E, Coleman HR, et al. Genotype-phenotype correlation in von Hippel-Lindau disease with retinal angiomatosis. Arch Ophthalmol 2007; 125(2): 239-45.

[12] Ong KR, Woodward ER, Killick P, Lim C, Macdonald F, Maher ER Genotype-phenotype correlations in von Hippel-Lindau disease. Hum Mutat 2007; 28(2): 143-9.

[13] Nicolaij D, Vogel-Kerebyn C, van den Bergh R, Steeno OP. Bilateral epididymal cysts as the first clinical manifestation of von HippelLindau-disease:a case report. Andrologia 1979; 11(3): 234-5.

[14] Kroes HY, Sijmons RH, Van Den Berg A, Van Der Hout AH. Earlyonset renal cell cancer and bilateral epididymal cysts as presenting symptoms of von Hippel-Lindau disease. Br J Urol 1998; 81(6): 915.

[15] Choyke PL, Glenn GM, Wagner JP, et al. Epididymal cystadenomas in von Hippel-Lindau disease. Urology 1997; 49(6): 926-31.

[16] Choyke PL, Glenn GM, Walther MM, et al. The natural history of renal lesions in von Hippel-Lindau disease: a serial CT study in 28 patients. AJR Am J Roentgenol 1992; 159(6): 1229-34.

[17] Hammel PR, Vilgrain V, Terris B, et al. Pancreatic involvement in von Hippel-Lindau disease. The Groupe Francophone d'Etude de la Maladie de von Hippel-Lindau. Gastroenterology 2000; 119(4): 1087-95.

[18] Hough DM, Stephens DH, Johnson CD, Binkovitz LA. Pancreatic lesions in von Hippel-Lindau disease: prevalence, clinical significance, and CT findings. AJR Am J Roentgenol 1994; 162(5): 1091-4.

[19] Neumann HP, Dinkel E, Brambs H, et al. Pancreatic lesions in the von Hippel-Lindau syndrome. Gastroenterology 1991; 101(2): 465-71.

[20] Charlesworth M, Verbeke CS, Falk GA, Walsh M, Smith AM, MorrisStiff G. Pancreatic Lesions in von Hippel-Lindau Disease? A Systematic Review and Meta-synthesis of the Literature. J Gastrointest Surg 2012; 16(7): 1422-8.

[21] Hes F, Zewald R, Peeters T, et al. Genotype-phenotype correlations in families with deletions in the von Hippel-Lindau (VHL) gene. Hum Genet 2000; 106(4): 425-31. 